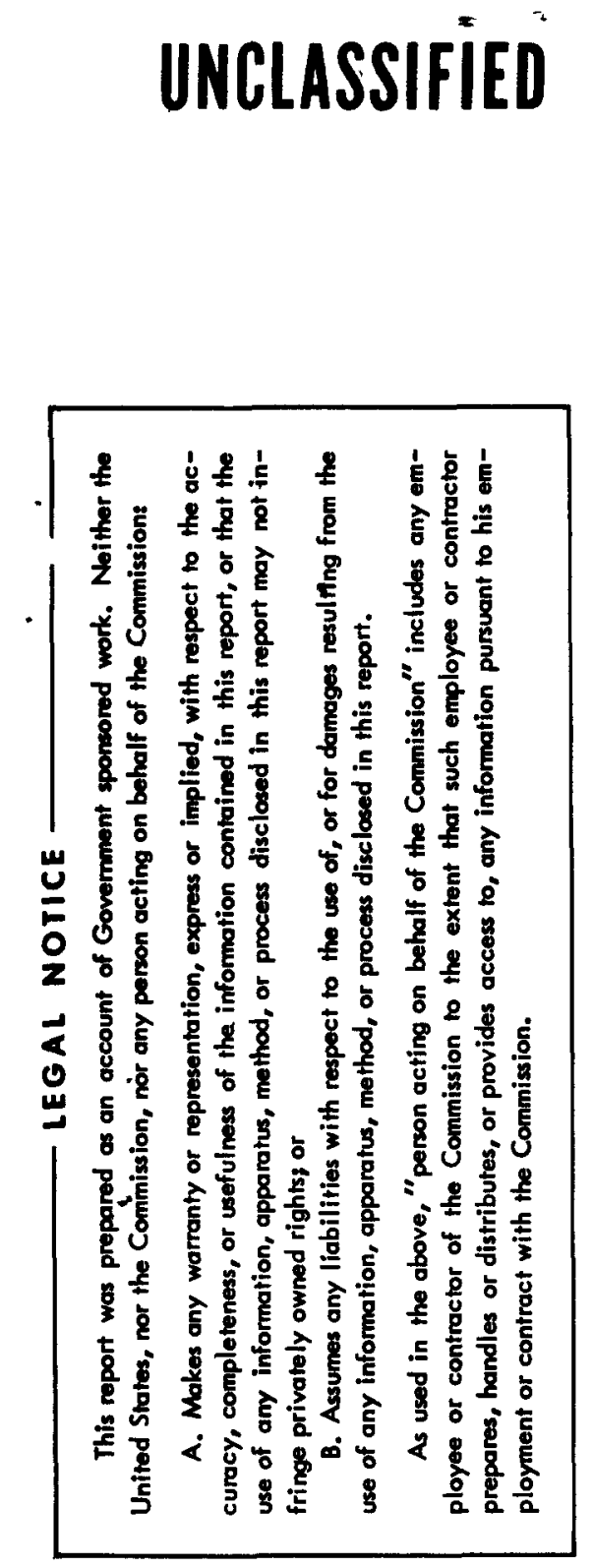

UNITED STATES ATOMIC ENERGY COMMISSION

SECOND QUARTERLY REPORT ON THE REDUCTIONS OF URANIUM OXIDES

By

Robert W. Bragdon

January 10, 1953

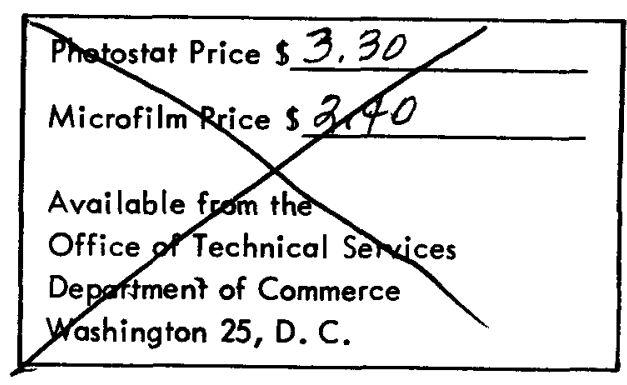

Metal Hydrides Incorporated

Chemical Research Laboratory

Beverly, Massachusetts

Technical Information Service Extension, Oak Ridge, Tenn.

This document is

PUBLICLY RELEASABLE
ORO Review Team
$\begin{aligned} & \text { Authorizing Ofincial } \\ & \text { Date } 11-9-2010\end{aligned}$




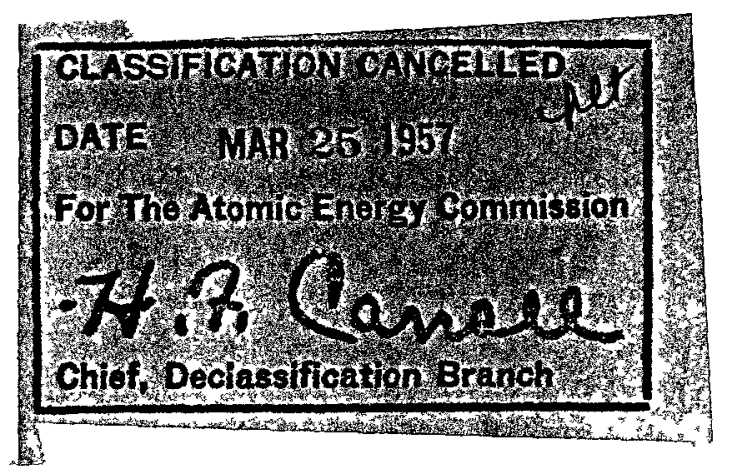




\section{DISCLAIMER}

This report was prepared as an account of work sponsored by an agency of the United States Government. Neither the United States Government nor any agency Thereof, nor any of their employees, makes any warranty, express or implied, or assumes any legal liability or responsibility for the accuracy, completeness, or usefulness of any information, apparatus, product, or process disclosed, or represents that its use would not infringe privately owned rights. Reference herein to any specific commercial product, process, or service by trade name, trademark, manufacturer, or otherwise does not necessarily constitute or imply its endorsement, recommendation, or favoring by the United States Government or any agency thereof. The views and opinions of authors expressed herein do not necessarily state or reflect those of the United States Government or any agency thereof. 


\section{DISCLAIMER}

Portions of this document may be illegible in electronic image products. Images are produced from the best available original document. 


\title{
NYO-3793 \\ t. \\ SECOND QUARTERLY REPORT ON THE \\ REDUCTIONS OF URANIUM OXIDES
}

By 2
Robert W. Bragdon

\begin{abstract}
The progress, during the second quarterly period, on a program designed to evaluate methods of preparing uranium hydride from the various oxides of uranium is presented. The current portion of the investigation is concerned with the reduction of $\mathrm{UO}_{2}, \mathrm{UO}_{3}$ and $\mathrm{U}_{3} \mathrm{O}_{8}$ with calcium hydride in an atmosphere of $\mathrm{H}_{2}$, and three such reductions are described. Chemical analyses of the products indicate that the reductions are incomplete under the specific conditions employed in these three runs. These conditions are the simplest and are not those which can be considered optimum. An apparently satisfactory standard laboratory leach method for the removal of the by-products has been evaluated, using a synthetic furnace product, and this method is currently being employed in the isolation of actual products. The evaluation of these products was seriously hindered by the difficulty in obtaining a sufficiently pure argon atmosphere for the dry box. The passage of tank argon over titanium sponge at $850^{\circ}-900^{\circ} \mathrm{C}$ has effectively solved this problem.
\end{abstract}

CHEMICAL RESEARCH STAFF

M. D. Banus

Robert W. Bragdon

David L. Henry

Harry O. Warren

January 10, 1953

Metal Hydrides, Incorporated

Chemical Research Laboratory

Beverly, Massqhusetts 
A. INTRODUCTION

The purpose of the current research program is to decrease the cost of production of uranium hydride. The present method of preparation is by the direct reaction of hydrogen with S.F. grade uranium metal. Uranium trioxide and urani um dioxide are prepared in an extreme1y pure state as intermediates in the preparation of the metal. The direct conversion of one of these oxides to uranium hydride in a one-step furnacing operation, or better stil1, by a continuous method, would eliminate several costly operations and might result in a considerabie price reduction. Three reducing agents are considered feasible for such a reduction. These are calcium hydride, calcium metal and magnesium meta1. Available information concerning the application of these reducing agents to uranium oxides is discussed more ful1y in Report NYO-3792. These reducing agents are being studied in the order above mentioned, and the work carried out to date is concerned on1y with calcium hydride.

It was mentioned in Report NY0-3792 that a necessary first step in this program was the development of a leach method for the removal of calcium oxide from the furnace products. A method employing a $10 \%$ aqueous acetic acid solution has proved satisfactory for the isolation of uranium hydride from a synthetic furnace product, and while this of course does not entirely duplicate the conditions to be met in the leach of an actual furnace product, it nevertheless appears that the uranium hydride is not noticeably affected by such a treatment.

The a11-metal_vacuum line described in detail in Report NYO3792 has been thoroughly tested in actual operation, and with only minor modifications has proved ideally suited to this study. While the present procedure calis for the preparation of approximately 75 grams of hydride per run, the apparatus can easily be ädaptęd to pound-scale preparition later. in the program.

The development o suitable dry box and handling technique for the extremely reaclive metal and hydride has been qute troublesome. While the tank rgon employed as an inert atmosphere in the dry box is of very hig purity, nevertheless it does contain sufficient oxygen $t p$ serious 1 contaminate tro small quantities of product which must be handied. The usual dry-box techniques have proved completely inadequate for our furposes, and tt has been necessary to spend a considerabie portion of time in dereloping methods of purification of the argon, both as it comes from the tank and also continuousiy after it has been introduced into the dry box. This latter purification is necessary because of the difficulty in coms. pletely flushing air from the box initially, and also because the neoprene gloves cannot be depended upon to be completely leak-proof in operation. Purification and handiing methods have now been deve1oped which overcome these difficulties.

Three reductions have been attempted during the past quarter1y

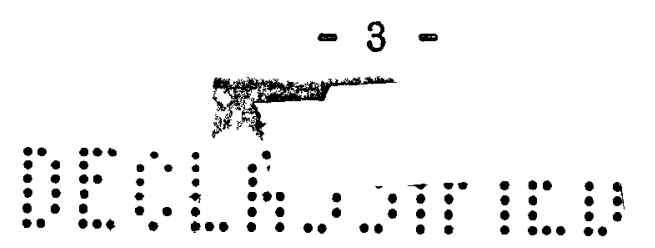


period, starting with each of the three oxides, $\mathrm{UO}_{2}, \mathrm{UO}_{3}$ and $\mathrm{U}_{3} \mathrm{O}_{8}$. In each case a large excess of calcium hydride has been employed, and the reduction has been carried out in an atmosphere of hydrogen at $950^{\circ} \mathrm{C}$. A standard 1aboratory 1 each method, described in the Appendix, was used for the isolation of the product from the excess reducing agent and the calcium oxide by-product. Chemical analyses of the products have indicated that incomplete reductions took place, and that each reduction took p1ace to about the same extent. These analyses indicate the presence of about 5\% oxygen, although this figure must be arrived at by difference. This point is discussed more fully below. The nitrogen content of these products is very nearly equal to the nitrogen contained in the calcium hydride employed for reductions, with the exception of the $\mathrm{UO}_{3}$ reduction. In this particular case the nitrogen content is severalfold larger, and apparentiy results from the conversion of uranyl nitrate hexahydrate to uranium nitride. The use of density measurement of uranium metal obtained by degassing the products as an indication of the oxide content could not be relied upon until our difficulties with the dry-box atmosphere had been completely overcome. Consequently we must rely on chemical analyses for hydrogen and uranium content for the evaluation of our products at this writing. This policy was dictated by the extreme reactivity of degassed uranium meta1. Such metal actively combines with oxygen or hydrogen at room temperature.

B. DISCUSSION

S.F. Materials

The S.F. materials needed for our present investigation were received early in this past quarterly period. They included 5 pounds of $\mathrm{UO}_{2}, 11$ pounds of $\mathrm{UO}_{3}$, and 5 pounds of uranium metal discs. In addition, we were permitted to transfer all S.F. matterials which had been in our possession under a recent $N_{0} E_{0} P_{0} A_{\text {. }}$ contract to the present $A_{\circ} E_{\circ} C_{0}$ contract. Among these materials, whitch included uranium meta1, thorium meta1 and thorium fluoride, were 4.35 pounds of S.F. uranium metal sticks. A letter from the Mallinckrodt Project Analytical Laboratory warned that the $\mathrm{UO}_{2}$ had been prepared severa1 years ago, and that it might have oxidized since then our analysis for free $\mathrm{UO}_{2}$, determined by the gain in weight uponignition to $\mathrm{U}_{3} \mathrm{O}_{8}$, indicated the "presence of $94.2 \%$ free U0 ${ }_{2}$. This, f course, is s1ight1y 1 ower than the usual $97-98 \%$, but it is not felt that this siight difference would be of any consequence in our evaluation. The $\mathrm{UO}_{3}$ was found to contain 99\% of the theoretical fmount of metal by ignition to $\mathrm{U}_{3} \mathrm{O}_{8}$. This would indicate the presence of about $1 \%$ of water or nitrates. The $\mathrm{UO}_{3}$ picked up $1.87 \%$ by weight when exposed to the 1aboratory atmosphere of 40-50\% relative humidity for twenty-four hours, and is, therefore, fairly hygroscopic。 We have prepared a 5-pound sample of $\mathrm{U}_{3} \mathrm{O}_{8}$ by ignition of a portion of the $\mathrm{UO}_{3}$ in a platinum dish at $850^{\circ} \mathrm{C}$ to constant weight. This material contained $99.6 \%$ of the theoretical amount of metal, as determined by a ceric sulphate titration of the tetravalent uranium, following the reduction with a lead reductor。

The preparation of uranium hydride from the recent1y acquired 


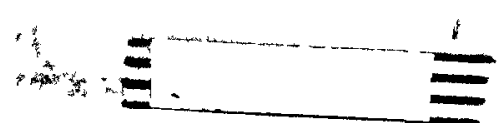

S.F. uranium metal has been more successful than with earlier preparations from A.R. grade metal. A typical analysis of material prepared from this S.F. metal is $98.7 \%$ uranium, $1.23 \%$ hydrogen, $0.17 \%$ carbon.

\section{Dry-Box Technique}

A dry box has been purchased by Metal Hydrides for the exclusive use of this contract. It was fabricated at Acme Industrial Company in Roxbury, Massachusetts, according to our own specifications. A complete description of this piece of equipment will be submitted after it has been thoroughly tested in this 1aboratory. The inert atmosphere employed is argon, and the analysis of this gas supplied to us by the producer is $99.9 \%$ argon, $0.02 \%$ oxygen, $0.04 \%$ hydrogen, with the balance nitrogen. While such purity might be wholly adequate for handiing reactive materials on a pound scale, the calculation of the possible contamination of a one-gram sample of uranium emphasizes the necessity of a purification method. The introduction of the oxygen and hydrogen contained in one cubic foot of this argon into a one-gram sample of uranium meta1 would result in $7 \% \mathrm{UO}_{2}$ and $8 \% \mathrm{UH}_{3}$. The density determination of degassed uranium hydride discussed later in the report gives evidence that contamination of this order does actually occur.

It was originally planned to use a NaK fountain inside the dry box proper, for the purpose of puyjfying the inert gas. This was discarded because it was reported $(1)$ to be somewhat troublesome, because of the tendency of the 1iquid metal to spray, and the consequent contamination of the box. Next, a continuous gas purifier patented after apparatus described by Klema $(2)$ was constructed and attached to the box. It consists of a verticle, $6^{n} 1$ ong, $31 / 2^{n} 0 . D$. stainless steel tube closed at the bottom and fitted with a blind flange at the top. It is connected with the dry box by means of $1^{n}$ $0 . D$. steel pipes extending from the sides of the tube, $1^{\text {" }}$ from the top and $1^{\prime \prime}$ from the bottom. The tube is loaded with calci um hydride, 6 to $10 \mathrm{mesh}$, and heated to $400^{\circ} \mathrm{C}$ by means of electrt cal resistance wire. As origina11y used by $\mathrm{K}$ lema (for the purification of argonhydrogen gas mixtures in a neutron spectrometer), the gas was circulated from the apparatus, through the purifier, and back to the apparatus by convection. While convection did circulate the argon in our box at the rate of about 15 1iters per hour, this was not near1y adequate, because of the large size of the box (over 8 cubic feet). In Klema's application the volume of argon to be purified was considerably less, and the complete purification occurred in a matter of minutes.

A sma11 blower and $1 / 4 \mathrm{~h} . \mathrm{p}$. motor has been purchased for the purpose of circulating the argon through the purifier at any desired rate. We plan to test the effectiveness of this purifier, loaded with 6 to 10 mesh calcium hydride, and operated at a temperature of

(1) UCRL-1463

(2) AECD -2157 
tosoc $400^{\circ} \mathrm{C}$. The effectiveness will be tested, using a NaK indicator. If calcium hydride does not prove to be satisfactory as a de-oxidizer, it will be replaced with titanium metal sponge and operated at $850^{\circ}$. $900^{\circ} \mathrm{C}--a$ technique which has proved successful for the purification of tank argon introduced to the box. This purification of the tank argon is carried out by passing the gas through a $2^{\circ}$ stain1ess steel tube, 3" O.D., loaded with titani um sponge, and heated to 8500-9000 by a Hevi-Duty muffle furnace. This temperature is believed to be sufficient1y high so that the oxides and nitrides formed on the surface will diffuse into the metal, thus prolonging the life of the getter. Titanium sponge was chosen, rather than one of several other likely gettering materials such as uranium turnings or zirconium powder, because of the ready availability, comparative 1 ow cost, and safety in handling. We have found that thorough flushing of the dry box with argon treated in this manner produces a dry-box atmosphere in which NaK retains a fresh metallic surface for considerable periods of time.

\section{Leach Eva1uations}

Two alternative methods (see Appendix) have proved satisfactory for the leaching of calcium oxide and calcium hydride from a synthetic furnace product. This artificial mix was prepared by mixing 241 parts of uranium hydride, 112 parts of calcium oxide, and 84 parts of calcium hydride; these being the proportions which would result from the reduction of uranium dioxide with a $100 \%$ excess of calcium hydride. One leach solution consists of a $10 \%$ acetic acid solution in de-aereated water, the other of a $10 \%$ hydrogen-ch1oride solution in anhydrous methanol. Both leaching techniques are carried out under an atmosphere of argon, the aqueous solution being used at $0{ }^{\circ} \mathrm{C}$ and the methanol solution at $-78^{\circ} \mathrm{C}$. While both methods are satisfactory, the aqueous acetic acid solution is to be preferred because of its ease of preparation, and a1so because the uranium hydride settles out much more rapidiy in this solution than it does in the methanol leach solution. In addition, the methano1-hydrogen chloride method cannot be recommended until the possibility that methy 1 chloride may be formed according to the raction

$$
\mathrm{CH}_{3} \mathrm{OH}+\mathrm{HCl} \longrightarrow \mathrm{CH}_{3} \mathrm{Cl}+\mathrm{H}_{2} \mathrm{O}
$$

has been fully investigated. Such a reaction might well occur in the presence of an excellent drying agent and a catalytic, metalif surface. The presence of a chlorinated hydrocarbon would of course be undesirabfe in the light of explosions reported with these types of systems.(1) A complete tabulation of the results obtained with both these methods appears in Tab1e $I_{0}$ In addition, one result is included in which an attempt was made to reduce the vigor of the reaction between calcium hydride and water by first covering the uranium hydride synthetic furnace product with dioxane, and then adding the leach solution to $i t$. It was found that the reaction could be much more easily controlled, and the yield and analytical results obtained

(1) Report CC-1059, Oct.9.1943 
with this method are quite promising. It is planned to compare this modification with a regular acetic acid technique with several actual furnace products, and if it lives up to its promise it will be adopted as the standard method in the future, since it greatiy facilitates the hydrolysis of the excess reducing agent.

\section{TABLE I}

$\mathrm{UH}_{3}$ Recovered From Synthetic Furnace Product

- No. Leach Method

1. HOAc- $\mathrm{H}_{2} \mathrm{O}$, alc.-ether wash

2 .

$2-a$

3.

$3-a$

4.

4-a

5. Water wash

6. Dioxane- $\mathrm{H}_{2} \mathrm{O}-\mathrm{HOAC}$

7. $\mathrm{HC} 1-\mathrm{MeOH}$ at $0^{\circ} \mathrm{C}$

8.

9. $\mathrm{HC} 1-\mathrm{MeOH}$ at $-78^{\circ} \mathrm{C}$

10 .

11.

12 .

13 .
$\%$ Yield $\% \mathrm{H} \% \mathrm{C}$ H corr.

Comment

$\begin{array}{llll}95.4 & 1.20 & 0.17 & 1.20\end{array}$

$\begin{array}{lllll}87.5 & 1.23 & 0.44 & 1.17) & \text { Temp. rose above } 0^{\circ} \mathrm{C}\end{array}$

$\begin{array}{llll}-- & 1.31 & 0.75 & 1.19)\end{array}$

from vigor of $\mathrm{Bx}$.

$78.4 \quad 1.23 \quad 0.63$

$1.13)$

Temp. rose above $0^{\circ} \mathrm{C}$ from vigor of $\mathrm{Rx}$.

$\begin{array}{llll}-- & 1.14 & 0.26 & 1.12)\end{array}$

$\begin{array}{llll}87.5 & 1.24 & 0.19 & 1.24\end{array}$

$\begin{array}{llll}-- & 1.27 & 0.23 & 1.25\end{array}$

$\begin{array}{llll}91.6 & 1.11 & 0.10 & 1.11\end{array}$

$\begin{array}{llll}87.5 & 1.22 & 0.16 & 1.22\end{array}$

(Reason for poor an(a1ysis unknown; (very smooth Rx.

$\begin{array}{llll}-- & 1.08 & 0.16 & 1.08\end{array}$

$\begin{array}{llll}94.0 & 1.16 & 0.48 & 1.12\end{array}$

$\begin{array}{llll}85.5 & 1.20 & 0.21 & 1.19\end{array}$

$\begin{array}{llll}95.0 & 1.27 & 0.39 & 1.22\end{array}$

$\begin{array}{llll}84.0 & 1.18 & 0.18 & 1.18\end{array}$

$\begin{array}{llll}95.0 & 1.23 & 0.38 & 1.19\end{array}$

$\begin{array}{llll}95.5 & 1.18 & 0.21 & 1.17\end{array}$

While the data in Table $I$ is self-explanatory, it is necessary to mention the basis of the corrected hydrogen value. The 1arge variation in both carbon and hydrogen analyses on duplicate samples of the same 1 each product suggested that these variations were caused by incomplete removal of the methanol or ether washes which are used in the preliminary drying of the furnace product. Since ether is the last of these solvents to contact the leach product, it would be expected to wash out any methanol 1 eft from the previous wash. A correction of the hydrogen values was thus made, assuming the carbon present to be due to incompletely removed ether, with an atomic ratio of hydrogen to carbon of 10 to 4 . In making these corrections, on $1 \mathrm{y}$ the 
carbon in excess of $0.17 \%$ was assumed to be present as ether. The carbon content of the original S.Fo uranium tal from which the urani um hydride for the synthetic furnace product was prepared has been shown to be $0.12 \%$ carbon. The average analysis of urani um hydride prepared from this material is $0.17 \%$ carbon. It is believed that this correction is necessary where the carbon exceeds $0.17 \%$, especial1y since in some of these cases the hydrogen value exceeds the theoretica1 $1.25 \%$ hydrogen content of uranium hydride. Furthermore, in every case where this correction was applied, duplicate corrected hvdrogen values are in good agreement, whereas several of the uncorrected values differ from one another by much greater than the experimental error of the analysis. It will be noted in Table $I_{8}$ which is arranged in roughly chronological order for each method, that this difficulty of contamination with the carbon compound (presumably ether) was encountered only in the early 1each studies, and has been avoided as experience with the technique has been acquired. The analyses of actual furnace products described later on show the presence of less than $0.1 \%$ carbon, so that it is probable that this correction will be unnecessary in the future.

\section{Reductions}

One reduction each of $\mathrm{UO}_{2}, \mathrm{UO}_{3}$ and $\mathrm{U}_{3} \mathrm{O}_{8}$ with calcium hydride, has been carried out by a procedure which is described in detail in the Appendix. Since time, temperature, reducing atmosphere, and excess of reducing agent are all variables which will be thoroughiy investigated in this program, the selection of conditions for these first experiments is more or less arbitrary, and these conditions are not necessarily those which are most apt to yield the best results. The yield and analytical results for the products obtained by the reduction of the three oxides, using the procedure described in detail in the Appendix, are tabulated in Table II. The values for $\% \mathrm{UH}_{3}$ in this table were calculated assuming that all of the hydrogen was present as uranium hydride. The values for $\% \mathrm{UO}_{2}$ were calculated assuming that the uranium that was not tied up as uranium hydride was present as uranium dioxide. These assumptions seem warranted, since in al1 three cases the sums of $\% \mathrm{UH}_{3}$ and $\% \mathrm{UO}_{2}$ are very near to $100 \%$.

\section{TABLE II}

UH3 Recovered from Leach Treatment of Freliminary Reductions under $\mathrm{H}_{2}$

$\begin{array}{ccccccccccc}\text { No. } & \text { Oxide } & \% \text { Yie1d } & \% \mathrm{U} & \% \mathrm{H} & \% \mathrm{C} & \% \mathrm{~N} & \% \mathrm{UH}_{3} & \% \mathrm{UO}_{2} & \text { Tota1 } \\ 1 & \mathrm{UO}_{2} & 61.9 & 94.0 & 0.80 & <0.1 & 0.0346 & 63.8 & 35.1 & 99.0 \\ 2 & \mathrm{UO}_{3} & 72.6 & 94.1 & 0.76 & <0.1 & 0.1156 & 60.6 & 38.8 & 99.6 \\ 3 & \mathrm{U}_{3} \mathrm{O}_{8} & 63.5 & 93.7 & 0.64 & <0.1 & 0.0479 & 51.1 & 49.0 & 100.2\end{array}$

A study of these results led to the following conclusions:

(1) The high oxide contents must be the result of incomplete reductions, since our studies with leach methods have shown that im- 
purities detectabie by chemical analysis are not introduced during that step.

(2) The oxide impurity must be either $\mathrm{UO}_{2}$ or $\mathrm{UO}_{3}$ since the reaction is carried out in an atmosphere of hydrogen, which is known to reduce other oxides to the $\mathrm{UO}_{2}$ state; and further, since no other stable oxygen-uranium phase exists under these conditions, to the best of our knowledge.

(3) The oxide impurity is probab1y $\mathrm{OO}_{2}$, since the calculation of uranium tied up as $\mathrm{UO}_{\text {, }}$ assuming the difference between the known analysis and $100 \%$ to be oxygen, ties up far too much uranium to permit the explanation of the remainder as uranium hydride in the light of the known hydrogen content.

(4) Ca1culation of part of the uranium as uranium hydride and the remainder as uranium dioxide results in a total analysis in each case which is very close to $100 \%$, and these calculated analyses are presented in Table II。

(5) Incomplete reduction must be the result of insufficient time at $950^{\circ} \mathrm{C}$ to attain equilibrium, or an attained equilibrium which is unfavorable。

It is apparent from a consideration of the nitrogen content of the products, and of the calcium hydride $(0.04 \%)$ used to prepare them, that ail of the calcium nitride is converted to uranium nitride during the furnacing operation, probably according to the reaction

$$
\mathrm{Ca}_{3} \mathrm{~N}_{2}+2 \mathrm{U} \longrightarrow 2 \mathrm{UN}+3 \mathrm{Ca} \text { 。 }
$$

The products of the reduction of $\mathrm{UO}_{2}$ and $\mathrm{U}_{3} \mathrm{O}_{8}$ contain nitrogen in amounts nearly equivalent to that introduced to the furnace charges as calcium nitride. The product of the reduction of $\mathrm{UO}_{3}$, however, is somewhat higher in nitrogen content, as had been anticipated, and this is no doubt due to the presence of nitrate in the $\mathrm{UO}_{3}$, which is converted to nitride during the furnacing operation. A calculation of the per cent of nitrogen introduced by the calcium hydride during the reduction of the $\mathrm{UO}_{3}$ sample still leaves approximately 800 parts per miliion of nitrogen unaccounted for, which it would seem must come from urany 1 nitrate hexahydrate in the original $\mathrm{UO}_{3}$ 。 800 parts per miliion of nitrogen from this source would requi re approximately $0.6 \%$ of water and nitrates, a not unreasonable figure in view of the 99.0\% assay obtained for that material. We are not in a position to say whether or not this high nitrate content would disqualify $\mathrm{UO}_{3}$ as a source of uranium hydride by the Hydrimet reduction. It should be pointed out, however, that this value exceeds by an order of magnitude the nitrogen content of uranium prepared by conventional techniques. See Report SEP-39。

While it may be possible to lower this nitrogen content in the regular production of $\mathrm{UO}_{3}$ by more careful furnacing, it would appear to be more desirable simply to furnace the $\mathrm{UO}_{3}$ at $8000^{\circ} \mathrm{C}$ or $900^{\circ} \mathrm{C}$,

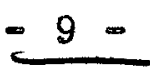


which operation would not only great1y reduce the nitrogen content, but would also convert the uranium to $U_{3} 0_{8}$, a compound which requires less reducing agent for the preparation of $\mathrm{UH}_{3}$.

\section{Density Data Determinations}

The helium densitometer described by Schumb and Rittner(1) has been adapted in our laboratories for the study of pyrophoric metal powders. The determination is based on the increase in pressure developed when helium gas is compressed into a known volume containing a weighed quantity of the unknown. The apparatus has been calibrated with mercury and checked with a standard sample of potassium acid phthalate. The 1iterature value for this compound is 1.634 grams per cc。at $20^{\circ} \mathrm{C}$. The density of the standard sample determined by the helium densitometer method is $1.634 \pm 0.002$ grams per cc。 at $27^{\circ} \mathrm{C}$. Before it was realized that the dry-box atmosphere was not pure enough for our purposes, it was attempted to measure the density of uranium powder prepared by degassing uranium hydride with a $1.23 \%$ hydrogen content prepared from S.F. uranium metal. A density approaching 18.90 grams per $c c$. was expected, since the original S.F. material ana1yzed $99.9 \%$ uranium, and $0.12 \%$ carbon. Actual1y, the value of 18.17 grams per cc. was obtained. Subsequent analysis of this powder by combustion technique showed the presence of 0.07 to $0.09 \%$ hydrogen; equivalent to 6 to $7 \% \mathrm{UH}_{3}$. With this quantity of hydride present, if one assumes that the density of the uranium metal-uranium hydride mixture decreases linearly with hydride content, one could not expect to get a density much greater than 18.3 grams per cc. We are not jet certain whether the hydrogen content of this metal resulted from incomplete degassing, or was introduced by the argon in the dry box. It seemed unlikely to us that such a degassing procedure would be capable of leaving much hydrogen in the metal, since it was degassed as high as $550^{\circ} \mathrm{C}$ for 12 hours. It will be noted, however, that the actual density obtained, as compared with the density to be expected.with this hydrogen content, stili suggests the presence of too great an amount of oxide, and emphasizes again the need for a pure dry ${ }^{-b o x}$ atmosphere. With our recent success in obtaining a pure dry-box atmosphere, this determination should prove a valuable tool in evaluating the purity of our products.

\section{CURRENT PLANS}

The conclusions reached after a study of the first three reductions point the way to modifications in technique that must be tried during the coming period. In order to determine whether or not the reductions were held at temperature for a sufficient period of time for equilibrium to be attained, the length of time of the reduction will be increased, holding al1 other variables the same. To investigate the possibility that equilibrium actually was at tained, but was an unfavorable one under the conditions employed, it is planned to try a technique developed earlier at Metal Hydrides Incorporated for use with the Hydrimet reduction. This technique involves the removal

(1) W. E. Schumb and E. S. Rittner, J。Am. Chem Soc。 65, 1692 (1943) $\ldots 10-10-$ 
of the hydrogen atmosphere from the furnace chargè while the charge is at temperature $\left(950^{\circ} \mathrm{C}\right)$, and replacing it with an atmosphere of argon, to prevent the distiliation of calcium. In this way, it is essentially calcium metal which completes the reduction and determines the extent to which the reduction proceeds. Since the reaction of the reducing agent with uranium probabiy depends upon the contact of calcium vapor with the oxides, it may be necessary to have an inert gas atmosphere over the furnace product, since the vapor pressure of calcium, practica1ly speaking, should be greater than in a hydrogen a tmosphere.

It is hoped that conditions will soon permit us to concentrate our efforts on the reduction of one of the three oxides of uranium, in order to permit a more rapid appraisal of the variables involved. It would seem reasonable to assume, for example, that any information gained concerning the proper conditions for the reduction of uranium dioxide would apply equaliy as well to the other two oxides. 


\section{APPENDIX}

\section{Aqueous Acetic Acid Leach Method}

A 50-gram samp1e of furnace product is weighed into a $150 \mathrm{cc}$. powder addition-buib in the dry box. This bulb is then attached to a 2-1iter, round bottom, three-necked flask by means of rubber tub ing. The 2-1iter flask is fitted with a true-bore, vacuum-type stirrer and a water-cooled bulb condenser. The apparatus is completely flushed out with argon, and $50 \mathrm{cc}$. of glacial acetic acid dissolved in $500 \mathrm{cc}$. of de-aerated water are added through the condenser. The flask is then chilled in an ice-salt bath, and the powder added slowly, adjusting the rate by a pinch-clamp on the rubber tubing. This operation requires some care, because of the tendency of the reaction to become too vigorous if large amounts of powder are added at any one time. When the reaction is complete, as evidenced by a cessation of the evolution of hydrogen, the solid product is washed by successive decantations with de-aerated, distilied water, protecting the sample as much as possible by a blanket of argon, and is dried in a vacuum desiccator by prolonged evacuation at room temperature. A11' subsequent handling for the purpose of obtaining yields and analytical data must be carried out in a scrupulously pure, argon-filled dry box.

\section{Dioxane-Acetic Acid Leach Method}

A 50-gram sample of furnace product is weighed directly into the 2-1iter flask in the dry box. The apparatus is assembled as described above, and $50 \mathrm{cc}$ of dioxane, previously dried over calcium hydride, are added to the furnace product through a separatory funnel. After the powder has become completely wetted, the flask is chilled in an ice bath to the freezing point of the dioxane, and water is added drop by drop, carefully controlling the rate of addition to avoid vigorous evolution of hydrogen. When hydrogen ceases to be evolved, water is added rapidiy until a total of $500 \mathrm{cc}$. have been introduced, and this is followed by the slow addition of $50 \mathrm{cc}$ of glacial acetic acid, controlling the rate of addition only so as to prevent the heating of the charge above $10^{\circ} \mathrm{C}$. The solid product is washed with a second wash of $50 \mathrm{cc}$. HAC in $500 \mathrm{cc}^{\circ} \mathrm{H}_{2} \mathrm{O}$, then with successive decantations with de-aerated, distilled water and is finally dried by washes with a1cohol followed by ether.

\section{Methan 01-Hydrogen Ch1 oride Leach Method}

A 50-gram sample of furnace product is weighed into $150 \mathrm{cc}$. powder addition bulb in the dry box. This bulb is then attached to a 21iter, round-bottom, three-neck flask by means of rubber tubing. The 2-1iter flask is fitted with a true-bore, vacuum-type stirrer and a waterocooled bulb condenser. The apparatus is completely flushed out with argon and $700 \mathrm{cc}$. of $10 \%$ hydrogen chloride solution and methanol are added. The flask is then chilled in a dry-ice, acetone bath to $-78^{\circ} \mathrm{C}$ and the powder is added slowly, adjusting the rate by a pinchclamp on the rubber tubing. After all the powder has been added, it 
is necessary to allow the reaction mixture to tharm up to $0^{\circ} \mathrm{C}$ for the reaction to go to completion. The solid product is washed by successive decantations with anhydrous methanol, and is finally dried by an ether wash, all the while protecting the sample as much as possible by a blanket of argon. The organic solvents are removed in a vacuum desiccator by evacuation at room temperature.

\section{Furnace Operation}

A sample of uranium oxide containing 71.4 grams $(0.3 \mathrm{~mole})$ of the metal is intimately mixed with a $100 \%$ excess of pulverized calcium hydride. The charge is loaded in a stainless steel boat, placed in a furnace tube, and a gasket and flange are then placed in position. The furnace tube is then attached to the vacuum line and evacuated at room temperature until the pressure has been reduced to 1 micron. The charge is then heated to $200^{\circ} \mathrm{C}$ and degassed for one hour with continuous pumping. Hydrogen is admitted to one atmosphere, and the furnace temperature raised directly to $950^{\circ} \mathrm{C}$, releasing the built-up pressure into the evacuated reservoir. The temperature is held at $950^{\circ} \mathrm{C}$ for two hours at one atmosphere of hydrogen. The reaction is cooled quickly to $300^{\circ} \mathrm{C}$, where it is held for one hour, and then cooled slowly to room temperature. The furnace tube is evacuated quickly, closed off at the stopcock, disassembled, and removed to the dry box. The charge is unloaded and samples transferred to a powder-addition bulb for the purposes of the leach method as described above. The remainder is stored in a waxed, screw-cap bottle.

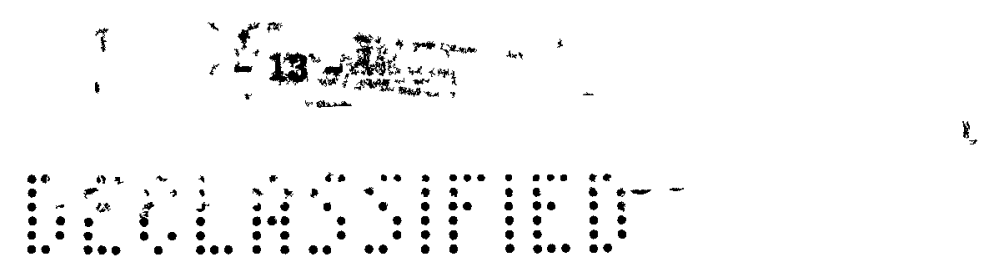


